\title{
ÁCIDO GIBERÉLICO, BISSULFURETO DE CARBONO E ÁCIDO 2-4 CLOROETIL FOSFÔNICO E A DORMÊNCIA E PRODUTIVIDADE DE TUBÉRCULOS DE BATATA
}

\author{
Ricardo Antonio Ayub ${ }^{1,4 *}$; Rui Scaramella Furiatti'; André Belmont Pereira²; Marie Y. Reghin'; \\ David Ariovaldo Banzatto²; Alessandra Valéria de Oliveira ${ }^{3,4}$ \\ ${ }^{1}$ Depto. de Fitotecnia e Fitossanidade - UEPG, Praça Santos Andrade, s/n - CEP: 84010-330 - Ponta Grossa, PR. \\ ${ }^{2}$ Depto. de Ciência do Solo e Engenharia Agrícola - UEPG. \\ ${ }^{3}$ Graduanda do Depto. de Biologia - UEPG. \\ ${ }^{4}$ Bolsista do CNPq. \\ *e-mail: rayub@uepg.br
}

RESUMO: Com o objetivo de avaliar a eficiência do ácido giberélico, bissulfureto de carbono e ácido 2-4 cloroetil-fosfônico (Ethrell ${ }^{R}$ ) na quebra de dormência e na produção de batata, cv. "Marijke", foi conduzido um ensaio no período de 1990/ $91 \mathrm{em}$ Piraí do Sul, PR . A superioridade do tratamento com o ácido 2-4-cloroetil-fosfônico em relação ao ácido giberélico e ao bissulfureto de carbono, aliada a sua facilidade de aplicação, justifica a sua recomendação com vistas a quebra de dormência de tubérculos do genótipo de batata em estudo, para a região de Piraí do Sul, PR, onde a dose de $842 \mathrm{mg} \cdot \mathrm{L}^{-1} \mathrm{de}$ Ethrell ${ }^{R}$ ocasionou a produção máxima de $23395 \mathrm{~kg} / \mathrm{ha}$.

Palavras-chave: Solanum tuberosum, batata, regulador vegetal, fisiologia vegetal

\section{GIBERELLIC ACID, CARBON-DISULPHIDE AND 2-4 CHLORO-ETHYL PHOSPHONIC AND THE DORMANCY AND YIELD OF POTATO TUBERS}

ABSTRACT: In order to evaluate the efficiency of giberellic acid, carbon-disulphide, and 2-4 chloroethyl phosphonic acid $\left(E t h r e I^{R}\right)$ on dormancy breaking and yield of potato cv. 'Marijke', an essay was conducted at Piraí do Sul, PR, Brazil, during 1990/1991. The superiority of the Ethrell ${ }^{R}$ treatment over giberellic acid and carbon-disulphide, and its easy application, justify its use for dormancy breaking of potato tubers, for the studied genotype and location, at the rate of $842 \mathrm{mg} . \mathrm{L}^{-1}$, resulting in a potato yield of 23,395 kg/ha.

Key words: Solanum tuberosum, potato, growth regulator, plant physiology

\section{INTRODUÇÃO}

Os tubérculos de batata, logo após a colheita, encontram-se dormentes, devido a um balanço hormonal entre promotores e inibidores de crescimento (Hemberg, 1985). Isto acarreta problemas técnicos aos plantios consecutivos realizados no centro-sul do Brasil. O período de dormência varia em função do cultivar, condições de cultivo e de armazenagem, danos mecânicos e outros fatores (Beukema \& Van der Zaag, 1979). Todos estes fatores relacionados ocasionam uma desuniformidade da cultura (Scholte, 1990) e consequentemente, diminuição de produtividade.

Vários métodos podem ser usados para quebrar a dormência da batata. Segundo Scholte (1990) o abafamento é eficiente na quebra de dormência do tubérculo. $O$ mesmo autor também recomenda o uso do bissulfureto de carbono; contudo, em doses elevadas este pode promover o apodrecimento dos tubérculos (Beukema \& Van der Zaag, 1979), possuindo ainda as desvantagens de exigir câmara hermética e ser um produto inflamável emuito tóxico (Bryan, 1989; Daniels et al., 1982).

Outro produto que além de quebrar a dormência pode evitar a dominância apical dos tubérculos (Lindblom, 1966) é o acido giberélico, que aplicado antes do início da brotação das gemas apicais promove maior uniformidade de brotação. Estes resultados foram confirmados por Bisognin et al. (1996). Também é conhecido o efeito do etileno na estimulação da saída do período de dormência (Latché et al., 1995).

O objetivo deste trabalho foi avaliar a eficiência do acido giberélico, bissulfureto de carbono e ácido 2-4 cloroetil-fosfônico em diferentes doses na quebra de dormência e na produção de tubérculos de batata, cv. Marijke, nas condições edafoclimáticas do município de Piraí do Sul, PR, Brasil. 


\section{MATERIAL E MÉTODOS}

O experimento foi conduzido na Fazenda Cumbuca, de propriedade do Sr. Hydeo Kayano, no ano de 1991, em Piraí do Sul, PR. Foram utilizados tubérculos-semente do tipo II fiscalizada, cv. Marijke. Os tubérculos encontravam-se dormentes no momento da aplicação dos tratamentos, tendo sido plantados em seguida. O plantio foi realizado em um latossolo vermelho amarelo, em 21/10/91 e a colheita em 12/01/92. Os tratos culturais foram efetuados de acordo com as recomendações para a cultura.

O delineamento experimental utilizado foi o de blocos ao acaso, em esquema fatorial $3 \times 5$, com três repetições. Os seguintes tratamentos foram testados: imersão por 10 minutos dos tubérculos semente em ácido giberélico $\left(\mathrm{PROGIBB}^{\mathrm{R}}\right)$ a 2, 4, 6, 8 e $10 \mathrm{mg}^{-\mathrm{L}^{-1}}$; imersão por 5 segundos em ácido 2 cloro etilfosfônico $\left(\right.$ Ethrell ${ }^{\mathrm{R}}$ ) a 100, 200, 400, 800 e 1000 mg. L $^{-1}$; aplicação de bissulfureto de carbono por $72 \mathrm{~h}$, nas doses 10, 20, 30, 40 e $50 \mathrm{~cm}^{3} \cdot \mathrm{m}^{-3}$ em estufa. A dose zero não foi utilizada, pois tem sido verificado que os tratamentos convencionais a base de ácido giberélico e bissulfureto de carbono são comprovadamente mais eficientes que a mesma (Meijers, 1972; Reghin, 1982).

Cada parcela foi constituída de 20 plantas, dispostas em 2 linhas com espaçamento de $0,75 \times 0,30 \mathrm{~m}$. Os parâmetros avaliados foram: número de hastes, stand final, número de flores/ parcela e produção de tubérculos/hectare.

\section{RESULTADOS E DISCUSSÃO}

$\mathrm{Na}$ TABELA 1 estão contidas as médias das variáveis observadas no experimento, mediante aplicação dos produtos nas suas respectivas doses.

Analisando os resultados obtidos para produção, verificou-se que a interação entre doses e produtos foi altamente significativa $\left(\bar{X}_{G}=5,51 ; C V=24,43 \% ; \alpha=1 \%\right)$, revelando, portanto, que existe efeito de produtos dentro das doses 2, 3, 4 e 5, observando-se que os produtos aplicados para a quebra de dormência de tubérculos de batata, respondem diferentemente dentro de tais doses em relação a produtividade da referida cultura. O tratamento a base de Ethrell ${ }^{\mathrm{R}}$, produziu $33 \%$ a mais que o tratamento a base de ácido giberélico e $52 \%$ mais que o tratamento a base de bissulfureto de carbono (TABELA 2).

Em função da interação significativa entre produtos e doses, conclui-se que existe efeito de doses do produto aplicado para a quebra de dormência sobre a produtividade da batata, quando os produtos utilizados são Ethrell $^{R}\left(\bar{X}_{G}=7,67 ; C V=16,94 \%\right)$ e ácido giberélico $\left(\bar{X}_{G}=5,12 ; C V=28,24 \%\right)$. Sendo assim, propõ̃e-se uma equação de estimativa de produção em função de dose dentro de Ethrell ${ }^{R}$ (equação 1) e ácido giberélico (equação 2). Onde $Y$ é a variável resposta produção e $\mathrm{X}$ a variável independente dose do produto.

TABELA 1 - Médias (de 3 repetições) do número de hastes (NH), número de flores (NF), stand final (SF)/ parcela e produção/hectare como resposta a aplicações de Ethrell, ácido giberélico e bissulfureto de carbono em batata cv. "Marijke". Piraí do Sul, PR, UEPG, 1991.

\begin{tabular}{lcccccc}
\hline PRODUTO & $\begin{array}{c}\mathrm{N}^{\circ} \mathrm{DE} \\
\text { ORDEM }\end{array}$ & DOSE & NH & NF & SF & $\begin{array}{c}\text { PRODUÇ } \tilde{O} \\
\text { (Kg/ha) }\end{array}$ \\
\hline Bissulfureto de Carbono & 1 & 10 & 1,55 & 10,66 & 15,66 & 8089 \\
\hline & 2 & 20 & 1,54 & 6,66 & 16,00 & 6911 \\
& 3 & 30 & 1,49 & 7,66 & 16,66 & 6689 \\
\hline Ethrell & 4 & 40 & 1,74 & 7,00 & 16,66 & 11489 \\
\hline & 5 & 50 & 2,01 & 8,33 & 16,00 & 8178 \\
\hline & 1 & 100 & 1,50 & 14,00 & 13,33 & 7578 \\
\hline Ácido Giberélico & 2 & 200 & 2,14 & 25,00 & 15,00 & 13489 \\
& 3 & 400 & 2,55 & 31,66 & 20,00 & 18689 \\
& 4 & 800 & 2,87 & 42,00 & 19,33 & 22067 \\
& 5 & 1000 & 3,03 & 29,66 & 19,66 & 23489 \\
\hline & 1 & 2 & 1,45 & 12,00 & 13,66 & 6422 \\
\hline & 2 & 4 & 1,72 & 19,33 & 16,33 & 13978 \\
& 3 & 6 & 2,05 & 23,30 & 16,66 & 11533 \\
& 4 & 8 & 2,06 & 22,66 & 13,66 & 14267 \\
\hline
\end{tabular}


TABELA 2 - Efeito da aplicação de bissulfureto de carbono, do ácido giberélico e do Ethrell ${ }^{\mathrm{R}}$ na produção de tubérculos de batata, cv. Marijke. Piraí do Sul, PR, UEPG, 1991.

\begin{tabular}{lc}
\hline \multicolumn{1}{c}{ PRODUTOS } & PRODUÇÃO $(\mathrm{Kg} / \mathrm{ha})$ \\
\hline Ethrell & $17067 \mathrm{~A}$ \\
Ácido Giberélico & $11378 \mathrm{~B}$ \\
$\begin{array}{l}\text { Bissulfureto de } \\
\text { Carbono }\end{array}$ & $8267 \mathrm{C}$ \\
\hline
\end{tabular}

*Médias seguidas pela mesma letra não diferem entre si a $1 \%$ de probabilidade pelo teste de Tukey.

\section{Equação 1}

$Y=4396,18+45,13 X-0,0268 X^{2} ; r^{2}=0,9712 ; F=6,35^{*}$

\section{Equação 2}

$Y=167,20+4115,31 X-306,49 \cdot X^{2} ; r^{2}=0,7147 ; F=6,11^{*}$

A dose de Ethrell que permitiu a obtenção da produção máxima da cultura de $23395 \mathrm{~kg} / \mathrm{ha}$, sob as condições edafo-climáticas em que o experimento foi conduzido, foi da ordem de $842 \mathrm{mg} \cdot \mathrm{L}^{-1}$. Entretanto, para o tratamento a base de ácido giberélico a produção máxima de 13981 $\mathrm{kg} / \mathrm{ha}$ foi obtida quando se adotou a dose de 6,71 $\mathrm{mg} \cdot \mathrm{L}^{-1}$.

Com base nos resultados obtidos para o número de hastes e número de plantas na colheita, constatou-se que a interação dose versus produto não foi significativa. Porém houve efeito de produtos (TABELA 3 ) e de doses, isoladamente.

TABELA 3 - Efeito da aplicação de bissulfureto de carbono, do ácido giberélico e do Ethrell $^{\mathrm{R}}$ no número de hastes, $\mathrm{n}^{0}$ de flores e de plantas/parcela, na colheita de tubérculos de batata, cv. Marijke. Piraí do Sul, PR, UEPG, 1991.

\begin{tabular}{lccl}
\hline PRODUTO & FLOR & $\begin{array}{c}\mathrm{N}^{\circ} \mathrm{DE} \\
\text { HASTES }\end{array}$ & $\begin{array}{c}\mathrm{N}^{\circ} \mathrm{DE} \\
\text { PLANTAS }\end{array}$ \\
\hline Ethrell & $28,46 \mathrm{~A}$ & $2,42 \mathrm{~A}$ & $17,80 \mathrm{~A}$ \\
$\begin{array}{l}\text { Ácido } \\
\text { Giberélico }\end{array}$ & $17,67 \mathrm{~B}$ & $1,87 \mathrm{~B}$ & $14,93 \mathrm{~B}$ \\
$\begin{array}{l}\text { Bissulfureto } \\
\text { de Carbono }\end{array}$ & $8,27 \mathrm{C}$ & $1,67 \mathrm{~B}$ & $16,20 \mathrm{AB}$ \\
\hline
\end{tabular}

*Médias seguidas pela mesma letra nas colunas não diferem entre si a $1 \%$ de probabilidade pelo teste de Tukey.
Observando-se a TABELA 3, referente a número de hastes $\left(\bar{X}_{G}=2,28 ; C V=11,63 \%\right.$; $\alpha=1 \%)$ e número de plantas $\left(\bar{X}_{G}=14,27\right.$; $\mathrm{CV}=9,99 \% ; \alpha=1 \%$ ), pode-se constatar que 0 tratamento a base de Ethrell ${ }^{R}$ foi significativamente superior aos demais, justificando desta forma o aumento da produção.

Com relação ao fator dose, o qual foi significativo mediante a aplicação do teste $F$, foi possível definir uma equação de regressão linear simples (eq. 3) dada por: $Y=1,3460+$ $0,2133 X, r^{2}=0,9789$, onde $Y$ é o número de hastes e $X$ é a dose do produto a ser aplicada $\left(\bar{X}_{G}=1,98 ; C V=19,03 \% ; \alpha=1 \%\right)$. No que tange ao número de plantas na colheita a equação definida (eq. 4) foi do tipo: $Y=11,4444+3,3682$ $X-0,4762 X^{2}, r^{2}=0,8636$, onde $Y$ é o número de plantas e $\mathrm{X}$ é a variável preditora já anteriormente definida $\left(\bar{X}_{G}=16,31 ; C V=14,12 \% ; \alpha=5 \%\right)$.

Em função da equação linear (eq. 3) para o número de hastes, não se pode definir a dose que assegura a melhor brotação. Já em relação ao número de plantas na colheita, a derivada da equação 4 , indica que a dose de 3,54 fornece o maior número de plantas, independentemente do produto aplicado. Ressalta-se que a dose de 3,54 é equivalente a interpolação entre as doses de 6 e 8 ppm de ácido giberélico, correspondente a $7,08 \mathrm{ppm}$, e com um stand de 11,42 plantas/ parcela, equivalente a 25378 plantas/ha.

No que tange aos resultados obtidos para a variável flor, mediante a aplicação do teste $F$, verificou-se que a interação entre os fatores em estudo foi significativa $\left(\bar{X}_{G}=28,47 ; C V=28,47\right.$; $\alpha=5 \%)$ e, de acordo com o teste de Tukey (TABELA 3), a média do tratamento à base de Ethrell $^{R}$ suplantou a média dos demais. O aumento do número de flores não foi prejudicial à produção. Este resultado pode ser decorrente de uma compensação pelo aumento do número de hastes e de plantas no tratamento à base de Ethrell ${ }^{R}$.

De posse dos resultados apresentados, concluiu-se que o tratamento à base de Ethrell ${ }^{R}$ é eficiente na quebra de dormência de tubérculos-semente e no aumento da produção de batata, cv. Marijke, sendo a equação de produção do tipo quadrática aquela que definiu que a dose de $842 \mathrm{mg} \cdot \mathrm{L}^{-1}$ de Ethrell ocasionou uma produção máxima de $23395 \mathrm{~kg} /$ hectare. A sua superioridade em relação ao ácido giberélico e ao bissulfureto de carbono, aliada a sua facilidade de aplicação, justifica a sua recomendação. Em função dos resultados promissores obtidos é importante que a dose de Ethrell ${ }^{\mathrm{R}}$ seja ajustada para outros cultivares e épocas de plantio. 


\section{AGRADECIMENTOS}

Ao $\mathrm{CNPq}$, pelas bolsas de Iniciação Cientifica e de Produtividade em Pesquisa concedidas à A. V. Oliveira e ao Dr. R.A. Ayub, respectivamente.

\section{REFERÊNCIAS BIBLIOGRÁFICAS}

BEUKEMA, H.P.; VAN DER ZAAG, D.E. Potato improvement: some factors and facts. Wageningen: International Agricultural Center, 1979. 224p.

BISOGNIN, D.; AMARANTE, C.; CANCI, P. Quebra de dormência e de dominância apical em batata. Horticultura Brasileira, v.14, p.23-26, 1996.

BRYAN, E.J. Ruptura del reposo en los tuberculos de papa. Lima: CIP, 15p. 1989. (Guía de Investigación CIP, 16).

DANIELS,J.; PATELLA, A.E.; LEAL, M. de L. da $S$. Métodos e efeitos de forçamento da brotação em batata. Pelotas: EMBRAPA, UEPAE, 1982. 7p. (Comunicado Técnico, 24).

HEMBERG, T. Potato rest. In: LI, P.H. Potato physiology. Orlando: Academic Press, 1985. p.353-388.
LATCHÉ, A.; AYUB, R.; MARTINEZ, G.; GUIS, M.; BENAMOR, M.; ROMBALDI, C.; PECH, JC.; BOUZAYEN, M. Biosynthèse et mode $d^{\prime}$ action de I'hormone végetal ethylène. Fruits, v.50, p.23-26, 1995.

LINDBLOM, $\mathrm{H}$. Apical dominance in relation to indole-3-acetic acid and giberellic acid. Zurich: Trienal Conference of European Association for Potato Research, 1966. p.184-185.

MEIJERS, C.P. Effect of carbon -disulphide on the dormancy and sprouting of seed potatoes. Potato Research, v.15, p.160-165, 1972.

REGHIN, M.Y. Estudo do forçamento químico da brotação em batatas-semente (Solanum tuberosum L.). Botucatu, 1982. 132p. Dissertação (Mestrado) - Faculdade de Ciências Agronômicas, Universidade Estadual Paulista.

SCHOLTE, K. Breaking dormancy of seed potatoes. Wageningen: International Agricultural Centre, 1990. 4p.

Recebido para publicação em 22.10 .98

Aceito para publicação em 01.09.99 